\title{
Synergic impact of oral anticoagulation control and renal function in determining major adverse events in atrial fibrillation patients undergoing percutaneous coronary intervention: insights from the AFCAS registry
}

\author{
Marco Proietti $^{1}$ - K. E. Juhani Airaksinen ${ }^{2}$ Andrea Rubboli ${ }^{3}$ Axel Schlitt ${ }^{4}$. \\ Tuomas Kiviniemi $^{5} \cdot$ Pasi P. Karjalainen ${ }^{6} \cdot$ Gregory Y. H. Lip $^{1,7} \cdot$ On behalf of the \\ AFCAS Study Group
}

Received: 13 October 2016 / Accepted: 21 December 2016 / Published online: 11 January 2017

(c) The Author(s) 2017. This article is published with open access at Springerlink.com

\begin{abstract}
Background In patients with atrial fibrillation (AF), quality of oral anticoagulation control as well as impaired renal function are associated with adverse outcomes. Our objective was to analyze if there was a synergistic impact of these factors in determining adverse outcomes in $\mathrm{AF}$ patients undergoing percutaneous coronary intervention and stent (PCI-S).

Methods Post-hoc analysis from the Atrial Fibrillation Undergoing Coronary Artery Stenting (AFCAS) registry. Poor oral anticoagulation control was defined as time in therapeutic range (TTR) $<65 \%$, while impaired renal function as creatinine clearance $(\mathrm{CrCl})<60 \mathrm{ml} / \mathrm{min}$.
\end{abstract}

Electronic supplementary material The online version of this article (doi:10.1007/s00392-016-1071-0) contains supplementary material, which is available to authorized users.

Gregory Y. H. Lip

g.y.h.lip@bham.ac.uk

1 University of Birmingham Institute of Cardiovascular Sciences, City Hospital, Dudley Road,

Birmingham B18 7QH, UK

2 Heart Center, Turku University Hospital and University of Turku, Turku, Finland

3 Division of Cardiology, Laboratory of Interventional Cardiology, Ospedale Maggiore, Bologna, Italy

4 Department of Medicine III, Martin Luther-University, Halle, Germany

5 Department of Cardiology, Paracelsus Harz-Clinic, Bad Suderode and Medical Faculty, Martin Luther-University Halle-Wittenberg, Halle, Germany

6 Heart Center, Satakunta Central Hospital, Pori, Finland

7 Aalborg Thrombosis Research Unit, Department of Clinical Medicine, Aalborg University, Aalborg, Denmark
Results Of the whole cohort, 448 were eligible for this post-hoc analysis. Of these, $27.9 \%$ had TTR $<65 \%$ only (Group I), $19.2 \%$ had $\mathrm{CrCl}<60 \mathrm{ml} / \mathrm{min}$ only (Group II), while $13.8 \%$ had both conditions (Group III). At followup, patients in Group III had a higher rate of major adverse cardiovascular and cerebrovascular events (MACCE) $(p=0.007)$, while patients in Groups I and III had higher rates of major bleeding. Kaplan-Meier analyses showed that patients in Group III had higher risk for MACCE (LogRank: 14.406, $p=0.003$ ), while Group I and Group III patients had higher risk for major bleeding (LogRank: 12.290, $p=0.006$ ). On Cox regression, presence of both conditions independently increased MACCE risk $(p=0.001)$, while TTR $<65 \%$ alone and the presence of both conditions were independently associated with major bleeding ( $p=0.004$ and $p=0.028$, respectively).

Conclusions There was a synergic impact of oral anticoagulation control and renal function in determining major adverse events in AF patients undergoing PCI-S. Use of poor anticoagulation control and impaired renal function in combination would help identify AF patients undergoing PCI-S at risk for MACCE and/or major bleeding.

Keywords Atrial fibrillation - Percutaneous coronary intervention · Quality of anticoagulation control · Renal impairment $\cdot$ Outcomes

\section{Introduction}

Atrial fibrillation (AF) is associated with a significant increase in thromboembolic and death risk [1,2]. Oral anticoagulant (OAC) therapy reduces major adverse coronary and cerebrovascular events (MACCE) in patients with AF 
[3]. Conversely, treatment with OAC confers a degree of bleeding risk [4].

Despite the introduction of non-vitamin $\mathrm{K}$ antagonist oral anticoagulants (NOACs), the vitamin $\mathrm{K}$ antagonist (VKA) is still widely used [5, 6]. Quality of OAC control, expressed as time in therapeutic range (TTR), is essential for optimal efficacy and safety [7]. Indeed, low TTR is significantly associated with higher stroke and bleeding rates [8]. Another significant factor influencing morbidity and mortality in AF patients is renal impairment, which itself is associated with higher thromboembolic and bleeding risks compared to those with normal renal function [9]. Of note, renal impairment can significantly influence TTR and its impact on major adverse events [10].

AF patients commonly have associated coronary artery disease, and may undergo percutaneous coronary intervention and stent (PCI-S) [3]. Such patients represent a particularly high-risk group for thromboembolism and bleeding, especially with the necessity to combine OAC with antiplatelet therapy [11]. We, therefore, hypothesized a synergic impact of poor TTR and renal impairment in determining adverse outcomes (MACCE, bleeding) in AF patients. We tested this hypothesis in a post-hoc analysis from the Atrial Fibrillation Undergoing Coronary Artery Stenting (AFCAS) registry.

\section{Methods}

AFCAS was a prospective multicentre European registry including AF patients undergoing PCI-S. Baseline and 1 year outcomes from AFCAS have previously been published $[12,13]$. In brief, all patients with on-going or history of AF referred for a PCI-S procedure were eligible to take part in the study. A 12-month follow-up observation period was planned to record all major adverse outcomes. Ethic approval and written informed consent was obtained from every patient, and the study protocol conforms to the 1975 Declaration of Helsinki. For this study, all patients that were prescribed with VKA and had TTR and data about renal function available were considered eligible for this ancillary analysis.

Thromboembolic risk was categorized according to $\mathrm{CHA}_{2} \mathrm{DS}_{2}$-VASc score [14]. "Low-risk" patients were defined as males with a $\mathrm{CHA}_{2} \mathrm{DS}_{2}-\mathrm{VASc}=0$ or females with $\mathrm{CHA}_{2} \mathrm{DS}_{2}-\mathrm{VASc}=1$; "moderate risk" was defined as male patients with $\mathrm{CHA}_{2} \mathrm{DS}_{2}$-VASc $=1$; and "high risk" with $\mathrm{CHA}_{2} \mathrm{DS}_{2}$-VASc $\geq 2$.

TTR was calculated according to the Rosendaal interpolation method [15]. INR considered for TTR calculation were performed at baseline and, subsequently at every follow-up visits (1, 3, 6, 12 months), when performed on-site. Poor anticoagulation control was defined as TTR $<65 \%$, consistent with previous studies [16, 17]. Renal function was evaluated according to $\mathrm{CrCl}$ calculated with the four-item Cockroft-Gault formula [(140-age) $\times$ (weight in $\mathrm{kg}) \times(0.85$ if female $) /(72 \times$ creatinine $)]$. Accordingly, an estimated $\mathrm{CrCl}$ level of $<60 \mathrm{ml} / \mathrm{min}$ was used to define impaired renal function, again based on established guidelines [18].

Based on the original protocol, the principal efficacy outcome was a composite of MACCE, including acute MI, target vessel revascularization, stroke/transient ischemic attack (TIA), systemic embolic event, stent thrombosis and cardiovascular death. Acute MI was defined according to the universal definition in use at the time of the study [19]. Target vessel revascularization was defined as PCI-S or coronary bypass surgery in the previously treated vessel. Stent thrombosis was defined according to the Academic Research Consortium classification and included definite and probable events [20]. TIA was defined as a focal, transient $(<24 \mathrm{~h})$ neurological deficit adjudicated by a neurologist, whereas stroke was defined as a permanent, focal, neurological deficit adjudicated by a neurologist and confirmed by computed tomography/magnetic resonance imaging. Systemic embolism was defined as signs/symptoms of peripheral ischemia associated or not with a positive imaging test. Cardiovascular death was defined as a death related to cardiac cause or stroke. The principal safety outcomes were 'major bleeding', defined as intracranial bleeding, bleeding requiring blood transfusion or surgical/endoscopic treatment or leading to long-term disability or death.

\section{Statistical analysis}

Continuous variables were reported as median [IQR] and differences between subgroups were assessed with Kruskal-Wallis one-way ANOVA test with pairwise comparisons between groups. Categorical variables, expressed as counts and percentages, were analysed by Chi-squared test.

Differences in survival between groups were examined with log-rank test and Kaplan-Meier curves were drafted accordingly. Cox regression analysis, adjusted for age, sex, type of $\mathrm{AF}, \mathrm{CHA}_{2} \mathrm{DS}_{2}$-VASc score and antithrombotic therapy pattern at discharge, was performed to establish the relationship between TTR, $\mathrm{CrCl}$ and their synergic effect in determining MACCE during follow-up observation. A two-sided $p$ value $<0.05$ was considered statistically significant. The sensitivity and specificity of using TTR $<65 \%$ and $\mathrm{CrCl}<60 \mathrm{ml} / \mathrm{min}$ alone or the combination of both was performed, to identify those AF patients undergoing PCI-S who are more likely to have a major adverse event during follow-up. All analyses were performed using SPSS v. 22.0 (IBM, NY, USA). 


\section{Results}

Among 963 patients enrolled in the study original cohort, $448(46.5 \%)$ were eligible for this post-hoc ancillary analysis. Of these $125(27.9 \%)$ had a TTR $<65 \%$ only (Group I), $86(19.2 \%)$ had a $\mathrm{CrCl}<60 \mathrm{ml} / \mathrm{min}$ only (Group II), while $62(13.8 \%)$ had both conditions, i.e., TTR $<65 \%$ and $\mathrm{CrCl}<60 \mathrm{ml} / \mathrm{min}$ (Group III). Conversely, 175 (39.1\%) patients had none of the two criteria (Group IV).

Baseline conditions are shown in Table 1. Patients in Groups II and III were older $(p<0.001)$ and more likely female $(p<0.001)$, and had lower BMI compared to those in Group I and IV $(p<0.001)$. Except for proportion of patients with diabetes mellitus, that was higher in Group I ( $p=0.025)$, baseline characteristics were similar across the four groups. Given the difference in age and proportion of female patients, the mean $\mathrm{CHA}_{2} \mathrm{DS}_{2}-\mathrm{VASc}$ score was higher in Groups II and III $(p<0.001)$, as was the proportion with high thromboembolic risk $\left(\mathrm{CHA}_{2} \mathrm{DS}_{2}-\mathrm{VASc} \geq 2\right) \quad(p<0.001)$. No significant differences were found in the prescription $(p=0.867)$ or duration $(p=0.215)$ of antithrombotic therapy across the four groups (Table 1).

\section{Follow-up}

After a median [IQR] follow-up time of 359 [342-369] days, a total of 76 (17.0\%) MACCE and 24 (5.4\%) major bleeding events were recorded, with an overall incidence of 18.7 per 100 patient-years and 5.7 per 100 patient-years, respectively. Comparing the four subgroups, Group III had a higher MACCE rate compared to other groups $(p=0.007)$ [Fig. 1, Left Side]. For major bleeding events, Groups I and III had higher event rates compared to other groups $(p=0.006)$ [Fig. 1, right side]. Details about individual MACCE are reported in Table S1. A significant higher rate of cardiovascular death was found in Group III $(p<0.001)$ compared to other groups.

Kaplan-Meier analyses showed that when both conditions were present (Group III) there was a higher risk for MACCE (og rank: 14.046, $p=0.003$ ) compared to other groups [Fig. 2, Panel a]. TTR $<65 \%$ alone (Group I) and both conditions together (Group III) had higher risk for major bleeding (log rank: 12.290, $p=0.006$ ) [Fig. 2, Panel b].

On Cox regression analysis (Table 2), the presence of both conditions (i.e., TTR $<65 \%$ and $\mathrm{CrCl}<60 \mathrm{ml} / \mathrm{min}$ ) independently increased MACCE risk $(p=0.001)$, while TTR $<65 \%$ and the presence of both conditions (i.e., TTR $<65 \%$ and $\mathrm{CrCl}<60 \mathrm{ml} / \mathrm{min}$ ) were independently associated with major bleeding $(p=0.004$ and $p=0.028$, respectively).

\section{Sensitivity and specificity}

For MACCE occurrence, TTR $<65 \%$ had a sensitivity of $50.0 \%$ (95\% CI: 38.3-61.7\%) and specificity of $60.0 \%$ (95\% CI: $54.8-65.0 \%) . \mathrm{CrCl}<60 \mathrm{ml} / \mathrm{min}$ had a sensitivity of $43.4 \%$ (95\% CI: $32.1-55.3 \%$ ) and specificity of $69.1 \%$ (95\% CI: $64.1-73.8 \%)$. The combination had a higher specificity (88.7\%, 95\% CI: 85.1-91.7\%), but lower sensitivity (26.3\%, 95\% CI: $16.9-37.7 \%)$.

For major bleeding occurrence, the combination had low sensitivity $(20.8 \%, 95 \%$ CI: $7.1-42.2 \%)$ but high specificity $(86.6 \%, 95 \%$ CI: $82.9-89.7 \%)$, compared to TTR $<65 \%$ only (sensitivity $75.0 \%$, 95\% CI: $53.3-90.2 \%$; specificity $60.1 \%, 95 \%$ CI: $55.3-64.8 \%$ ) or $\mathrm{CrCl}<60 \mathrm{ml} / \mathrm{min}$ only (sensitivity $33.3 \%$, 95\% CI: $15.6-55.3 \%$; specificity $67.0 \%$, 95\% CI: $62.3-71.4 \%)$.

\section{Discussion}

In this post-hoc ancillary analysis from the AFCAS study, our main finding was that the concomitant presence of both poor OAC control (TTR $<65 \%)$ and impaired renal function $(\mathrm{CrCl}<60 \mathrm{ml} / \mathrm{min})$ independently increased the occurrence of MACCE. For major bleeding, the presence of both conditions was again an independent risk factor, while poor OAC control per se was an independent risk factor for major bleeding, but not renal impairment. Using poor anticoagulation control and impaired renal function in combination would help identify AF patients undergoing PCI-S who are at risk of having a MACCE and/or a major bleeding event during follow-up.

The relationship between renal impairment and adverse events in AF patients has been well-established [9]. Several pathophysiological mechanisms have been proposed in determining the higher thromboembolic and bleeding risks in AF patients with chronic kidney disease (CKD) [9]. More recent evidence shows how progressive worsening of renal function is associated with changes in fibrin clot structure, leading to a progressive higher clot density [21]. Unsurprisingly, epidemiological and clinical trial data clearly demonstrate that in AF patients, CKD increases the risk of stroke [10, 22-26]. Indeed, "impaired renal function" was proposed to increase the predictive ability of stroke risk prediction scoring schemes in a highly selected anticoagulated trial cohort [27]. Despite a modest statistical improvement in predictive ability of clinical scores in the original derivation cohort, this approach was not validated in large "real-world" independent cohorts of AF patients [28, 29].

A recent meta-analysis provides evidence that warfarin treatment reduces the risk of thromboembolic events in AF patients with CKD [hazard ratio (HR): 0.39, 95\% 
Table 1 Baseline characteristics of study cohort

\begin{tabular}{|c|c|c|c|c|c|}
\hline & $\begin{array}{l}\text { Group I TTR }<65 \% \text {, } \\
n=125\end{array}$ & $\begin{array}{l}\text { Group II } \\
\mathrm{CrCl}<60 \mathrm{ml} / \\
\min , n=86\end{array}$ & $\begin{array}{l}\text { Group III Both } \\
\text { conditions, } n=62\end{array}$ & $\begin{array}{l}\text { Group IV Nei- } \\
\text { ther TTR }<65 \% \text { or } \\
\mathrm{CrCl}<60 \mathrm{ml} / \mathrm{min} \text {, } \\
n=175\end{array}$ & $p$ \\
\hline Age, (years) median [IQR] & $72[66-75]^{\mathrm{a}}$ & $79[74-83]^{\mathrm{b}}$ & $78[74-80]^{\mathrm{b}}$ & $71[63-77]^{\mathrm{a}}$ & $<0.001$ \\
\hline Female, $n(\%)$ & $29(23.2)$ & $38(44.2)$ & $23(37.1)$ & $35(20.0)$ & $<0.001$ \\
\hline BMI, $\left(\mathrm{kg} / \mathrm{m}^{2}\right)$ median [IQR] 433 & $29[26-32]^{\mathrm{a}}$ & $25[23-28]^{\mathrm{b}}$ & $26[24-29]^{b}$ & $29[26-31]^{\mathrm{a}}$ & $<0.001$ \\
\hline $\mathrm{CrCl},(\mathrm{ml} / \mathrm{min})$ median $[\mathrm{IQR}]$ & $80.9[69.6-109.0]^{\mathrm{a}}$ & $\begin{array}{c}48.5[39.9- \\
55.0]^{\mathrm{b}}\end{array}$ & $46.3[35.1-51.7]^{\mathrm{b}}$ & $84.3[70.8-106.3]^{\mathrm{a}}$ & $<0.001$ \\
\hline TTR, $(\%)$ median [IQR] & $37.4[16.1-50.0]^{\mathrm{b}}$ & $92.7[81.0-100]^{\mathrm{a}}$ & $37.7[8.2-53.7]^{\mathrm{b}}$ & $98.9[86.2-100]^{\mathrm{a}}$ & $<0.001$ \\
\hline AF Type, $n(\%) 444$ & & & & & 0.531 \\
\hline Paroxysmal & $39(31.7)$ & $29(34.1)$ & $16(25.8)$ & $42(24.1)$ & \\
\hline Persistent & $13(10.6)$ & $5(5.9)$ & $7(11.3)$ & $18(10.3)$ & \\
\hline Permanent & $71(57.7)$ & $51(60.0)$ & $39(62.9)$ & $114(65.5)$ & \\
\hline Hypertension, $n(\%)$ & $101(80.8)$ & $71(82.6)$ & $52(83.9)$ & $132(75.4)$ & 0.373 \\
\hline Hypercholesterolemia, $n(\%)$ & $81(64.8)$ & $53(61.6)$ & $40(64.5)$ & $120(68.6)$ & 0.716 \\
\hline Diabetes mellitus, $n(\%)$ & $52(41.6)$ & $24(27.9)$ & $18(29.0)$ & $45(25.7)$ & 0.025 \\
\hline Smoking habit, $n(\%)$ & $14(11.2)$ & $4(4.7)$ & $4(6.5)$ & $15(8.6)$ & 0.363 \\
\hline Previous coronary artery disease, $n(\%)$ & $45(36.0)$ & $31(36.0)$ & $23(37.1)$ & $56(32.0)$ & 0.830 \\
\hline Previous MI, $n(\%)$ & $35(28.0)$ & $24(27.9)$ & $17(27.4)$ & $35(20.0)$ & 0.318 \\
\hline Previous PCI, $n(\%)$ & $19(15.2)$ & $10(11.6)$ & $7(11.3)$ & $23(13.1)$ & 0.844 \\
\hline Previous CABG, $n(\%)$ & $21(16.8)$ & $12(14.0)$ & $15(24.2)$ & $28(16.0)$ & 0.396 \\
\hline Chronic heart failure, $n(\%)$ & $26(20.8)$ & $19(22.1)$ & $13(21.0)$ & $26(14.9)$ & 0.405 \\
\hline Ejection fraction, (\%) median [IQR] 323 & $50[40-60]$ & $50[40-58]$ & $50[40-60]$ & $51[40-60]$ & 0.507 \\
\hline Previous stroke/TIA, $n(\%)$ & $20(16.0)$ & $19(22.1)$ & $13(21.0)$ & $36(20.6)$ & 0.672 \\
\hline Previous bleeding, $n(\%)$ & $5(4.0)$ & $4(4.7)$ & $1(1.6)$ & $10(5.7)$ & 0.595 \\
\hline $\mathrm{CHA}_{2} \mathrm{DS}_{2}$-VASc, median [IQR] & $3[2-5]^{\mathrm{a}}$ & $4[3-5]^{\mathrm{b}}$ & $4[3-5]^{\mathrm{b}}$ & $3[2-4]^{\mathrm{a}}$ & $<0.001$ \\
\hline Thromboembolic risk, $n(\%)$ & & & & & $<0.001$ \\
\hline Low risk & $0(0)$ & $0(0)$ & $0(0)$ & $5(2.9)$ & \\
\hline Moderate risk & $11(8.8)$ & $0(0)$ & $0(0)$ & $24(13.7)$ & \\
\hline High risk & $114(91.2)$ & $86(100.0)$ & $62(100.0)$ & $146(83.4)$ & \\
\hline \multicolumn{6}{|l|}{ PCI clinical indication, $n(\%)$} \\
\hline Stable angina & $59(47.2)$ & $31(36.0)$ & $25(41.0)$ & $91(52.0)$ & \\
\hline NSTE-ACS & $43(34.4)$ & $34(39.5)$ & $27(44.3)$ & $62(35.4)$ & \\
\hline STEMI & $15(12.0)$ & $17(19.8)$ & $8(13.1)$ & $14(8.0)$ & 0.137 \\
\hline Other & $8(6.4)$ & $4(4.7)$ & $1(1.6)$ & $8(4.6)$ & \\
\hline PCI clinical setting, $n(\%)$ & & & & & 0.158 \\
\hline Emergency & $63(50.4)$ & $34(39.5)$ & $29(46.8)$ & $99(56.6)$ & \\
\hline Urgency & $44(35.2)$ & $38(44.2)$ & $25(40.3)$ & $62(35.4)$ & \\
\hline Elective & $18(14.4)$ & $14(16.3)$ & $8(12.9)$ & $14(8.0)$ & \\
\hline $\mathrm{N}^{\mathrm{o}}$ diseased vessels, median [IQR] 447 & $2[1-3]$ & $2[1-3]$ & $2[1-3]$ & $2[1-3]$ & 0.684 \\
\hline $\mathrm{N}^{\mathrm{o}}$ treated vessels, median [IQR] & $1[1-1]^{\mathrm{a}}$ & $1[1-1]^{\mathrm{a}}$ & $1[1-1]^{\mathrm{a}}$ & $1[1-1]^{\mathrm{a}}$ & 0.049 \\
\hline Lesion severity, $n(\%) 414$ & & & & & 0.080 \\
\hline A & $23(20.9)$ & $8(10.3)$ & $8(14.8)$ & $24(14.0)$ & \\
\hline B1/B2 & $68(61.8)$ & $59(75.6)$ & $32(59.3)$ & $103(59.9)$ & \\
\hline $\mathrm{C}$ & $19(17.3)$ & $11(14.1)$ & $14(25.9)$ & $45(26.2)$ & \\
\hline Complete revascularization, $n(\%) 440$ & $60(49.6)$ & $35(40.7)$ & $24(40.7)$ & $89(51.1)$ & 0.280 \\
\hline Stent type, $n(\%) 434$ & & & & & 0.196 \\
\hline DES & $28(23.7)$ & $14(16.9)$ & $19(30.6)^{\#}$ & $44(25.7)$ & \\
\hline Bioactive & $16(13.6)$ & $15(18.1)$ & $10(16.1)^{\#}$ & $42(24.6)$ & \\
\hline BMS & $70(59.3)$ & $49(59.0)$ & $31(50.0)^{\#}$ & $78(45.6)$ & \\
\hline
\end{tabular}


Table 1 (continued)

\begin{tabular}{lllll}
\hline & $\begin{array}{l}\text { Group I TTR }<65 \%, \\
n=125\end{array}$ & $\begin{array}{l}\text { Group II } \\
\mathrm{CrCl}<60 \mathrm{ml} / \\
\min , n=86\end{array}$ & $\begin{array}{l}\text { Group III Both } \\
\text { conditions, } n=62\end{array}$ & $\begin{array}{l}\text { Group IV Nei- } \\
\text { ther TTR }<65 \% \text { or } \\
\mathrm{CrCl}<60 \mathrm{ml} / \mathrm{min}, \\
n=175\end{array}$ \\
\hline $\begin{array}{l}\text { Other } \\
\text { Prescribed antithrombotic therapy, } n(\%)\end{array}$ & $4(3.4)$ & $5(6.0)$ & $2(3.2)^{\#}$ & $7(4.1)$ \\
$\begin{array}{l}\text { Single AP+VKA } \\
\text { Dual AP+VKA }\end{array}$ & $14(11.2)$ & $9(10.5)$ & $7(11.3)$ & $15(8.6)$ \\
Antithrombotic therapy duration, $n(\%)$ & $11(88.8)$ & $77(89.5)$ & $55(88.7)$ & $160(91.4)$ \\
0-3 months & $66(52.8)$ & $50(58.1)^{\#}$ & $30(48.4)$ & $83(47.4)^{\#}$ \\
3-6 months & $21(16.8)$ & $21(24.4)^{\#}$ & $11(17.7)$ & $41(23.4)^{\#}$ \\
$\geq 6$ months & $38(30.4)$ & $15(17.4)^{\#}$ & $21(33.9)$ & $51(29.1)^{\#}$ \\
\hline
\end{tabular}

a, b Differences in superscripts between the groups is related to significant differences in pairwise comparisons between groups

$A C S$ acute coronary syndrome, $A F$ atrial fibrillation, $B M S$ bare metal stent, $C A B G$ coronary artery by-pass graft, $C r C l$ creatinine clearance, $D E S$ drug eluting stent, IQR interquartile range, MImyocardial infarction, NSTEnon ST elevation, PCIpercutaneous coronary intervention, STEMIST elevation myocardial infarction, TIA transient ischemic attack, TTR time in therapeutic range

${ }^{\#}$ Total percentage is equal to $99.9 \%$ due to rounded figures

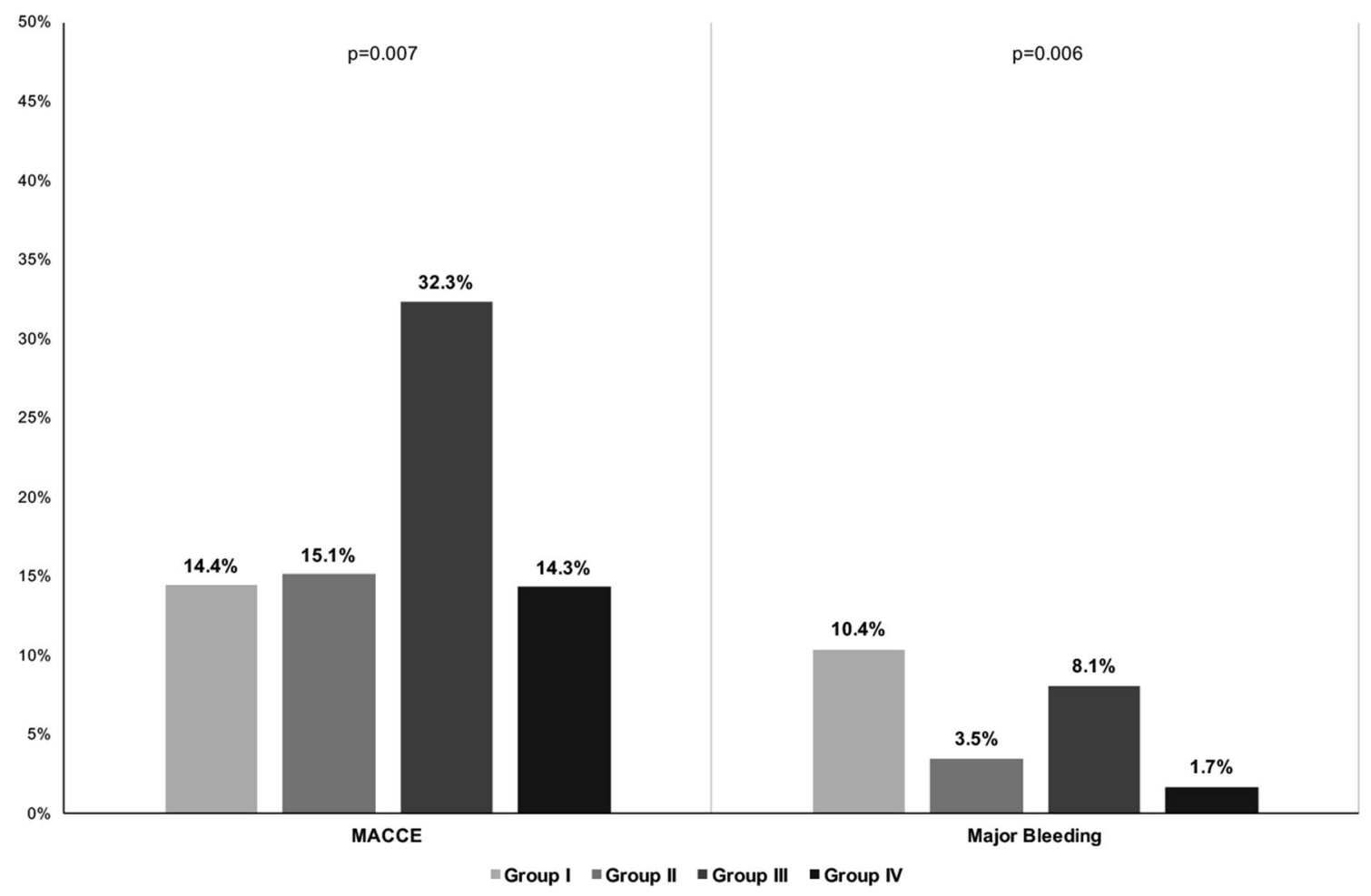

Fig. 1 Major adverse events rates according to presence of low-quality anticoagulation and moderate renal impairment. $\mathrm{CrClcreatinine} \mathrm{clear-}$ ance, MACCE major adverse coronary and cerebrovascular events, TTR time in therapeutic range

confidence interval (CI): 0.18-0.86, $p<0.00001]$ [30]. Indeed, Bonde et al. report a significant net clinical benefit for VKA amogst CKD patients at a high risk of thromboembolic events $\left(\mathrm{CHA}_{2} \mathrm{DS}_{2}-\mathrm{VASc} \geq 2\right)$ [25].
Paradoxically, a higher bleeding risk has also been reported in AF CKD patients [31,32].

VKA treatment is effective and safe when there is good quality OAC control [7]. A European Society of Cardiology Anticoagulation Task Force consensus statement 

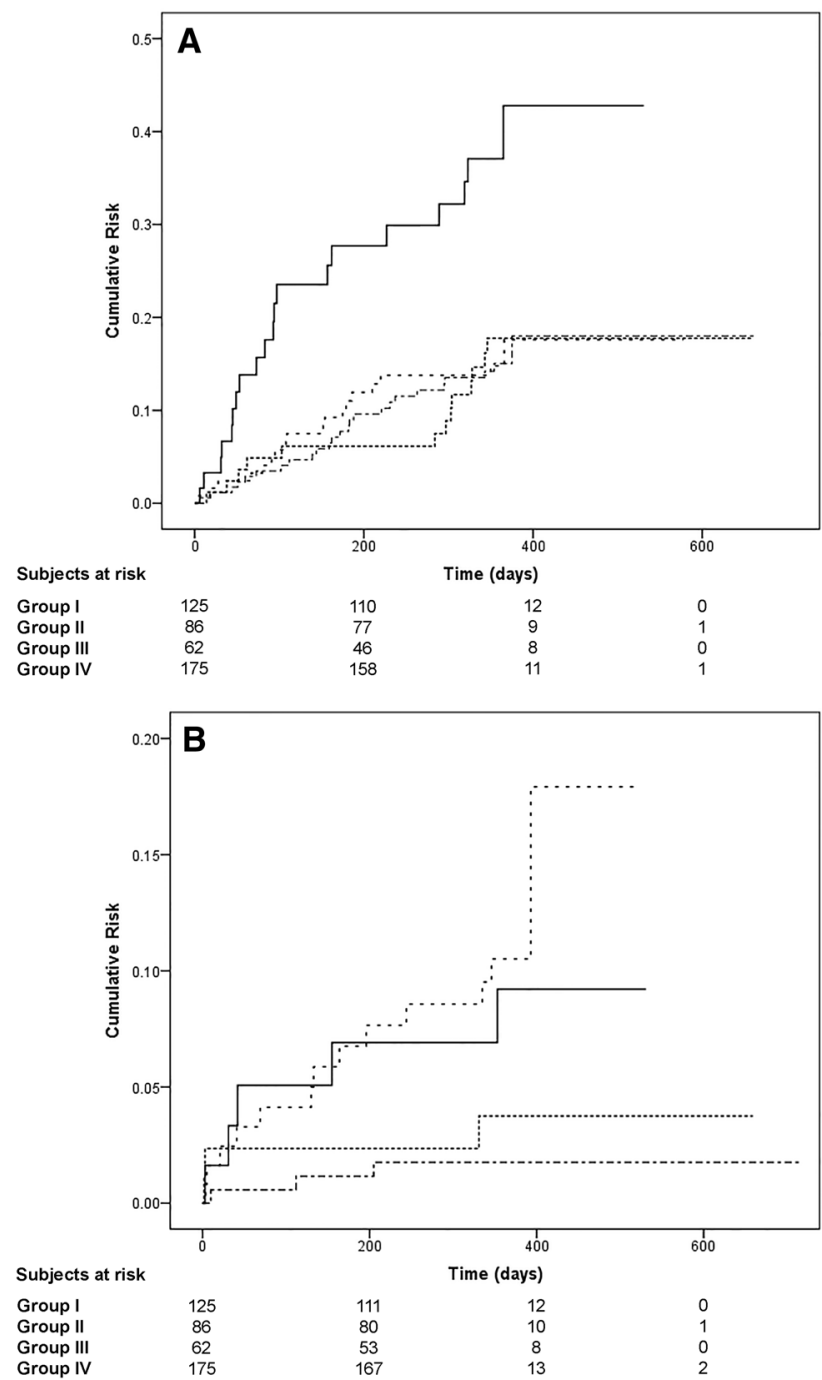

Fig. 2 Kaplan-Meier curves for major adverse events. Panel (a) MACCE; panel (b) major bleeding. Large dashes Group I, Narrow dashes Group II, Solid line Group III, Alternate dashes Group IV, $\mathrm{CrCl}$ creatinine clearance, $\mathrm{MACCE}$ major adverse coronary and cerebrovascular events, TTR time in therapeutic range

recommends that good anticoagulation control is defined as a TTR $>70 \%$ [33]. Indeed, lower TTR values are associated with higher risks of thromboembolic and bleeding events $[8,17,34,35]$.

A relationship between quality of OAC control and renal impairment has been reported. For example, an analysis coming from the Outcomes Registry for Better Informed Treatment of Atrial Fibrillation (ORBIT-AF) registry found that the presence of CKD was significantly associated with a low TTR [36]. In a post-hoc analysis from the Stroke Prevention using an Oral Thrombin Inhibitor in patients with atrial Fibrillation (SPORTIF) III and V trials, there was a significant linear relationship between $\mathrm{CrCl}$ (expressed with Cockroft-Gault equation)
Table 2 Cox regression analysis for major adverse events

\begin{tabular}{llll}
\hline & HR & $95 \%$ CI & $p$ \\
\hline MACCE & & & \\
TTR $<65 \%$ & 1.04 & $0.57-1.91$ & 0.896 \\
CrCl $<60 \mathrm{ml} / \mathrm{min}$ & 1.10 & $0.56-2.16$ & 0.776 \\
Both conditions & 2.62 & $1.46-4.72$ & 0.001 \\
None condition (reference) & - & - & - \\
Major bleeding event & & & \\
TTR $<65 \%$ & 6.24 & $1.83-22.58$ & 0.004 \\
CrCl $<60 \mathrm{ml} /$ min & 2.26 & $0.45-11.26$ & 0.318 \\
Both conditions & 4.96 & $1.18-20.78$ & 0.028 \\
None condition (reference) & - & - & - \\
\hline
\end{tabular}

Adjusted for age, sex, type of $\mathrm{AF}, \mathrm{CHA}_{2} \mathrm{DS}_{2}$-VASc score, antithrombotic therapy

$C I$ confidence interval, $\mathrm{CrCl}$ creatinine clearance, $H R$ hazard ratio, $T T R$ time in therapeutic range

and TTR [10]. Furthermore, the presence of CKD could modify the relationship between TTR and risk for both stroke and major bleeding, conferring a higher risk even with the same level of anticoagulation control [10].

The role of renal impairment in determining adverse outcomes amongst patients undergoing PCI-S has been demonstrated in general populations, both in terms of major cardiovascular events [37] and major bleeding [38]. Similar data have been already described in patients with AF receiving PCI-S [39]. The present study results, in the context of the available evidence, reinforces the concept that quality of OAC control and renal impairment are strongly interconnected in determining the occurrence of major adverse outcomes in AF patients undergoing PCIS. Our study also reinforces the importance of good quality OAC control in determining major bleeding amongst patients with renal impairment, at least in this specific clinical scenario.

\section{Limitations}

Main limitation to this study is its post-hoc observational nature. The relatively small numbers of patients and the lack of NOAC data could limit the generalizability of the results to contemporary clinical practice.

In conclusion, there was a synergic impact of OAC control and renal function in determining major adverse events (MACCE and major bleeding) in AF patients undergoing PCI-S. Use of poor anticoagulation control and impaired renal function in combination would help identify AF patients undergoing PCI-S who are at risk of MACCE and/or major bleeding. 
Declarations of interest MP: small consulting fee for Boehringer Ingelheim. TOK: consultant for Boehringer Ingelheim. Speaker for Bayer, BMS/Pfizer, Boehringer Ingelheim. GYHL: consultant for Bayer/Janssen, BMS/Pfizer, Biotronik, Medtronic, Boehringer Ingelheim, Microlife and Daiichi-Sankyo. Speaker for Bayer, BMS/Pfizer, Medtronic, Boehringer Ingelheim, Microlife, Roche and Daiichi-Sankyo. All other authors have nothing to disclose.

Funding AFCAS study was supported by unrestricted grants from Novartis Germany and Sanofi-Aventis Germany and by grants from the Finnish Foundation for Cardiovascular Research, Helsinki, Finland. No specific funding has been used to support this analysis.

Open Access This article is distributed under the terms of the Creative Commons Attribution 4.0 International License (http:// creativecommons.org/licenses/by/4.0/), which permits unrestricted use, distribution, and reproduction in any medium, provided you give appropriate credit to the original author(s) and the source, provide a link to the Creative Commons license, and indicate if changes were made.

\section{References}

1. Lip GYH, Lane DA (2015) Stroke prevention in atrial fibrillation. JAMA 313:1950-1962

2. Odutayo A, Wong CX, Hsiao AJ, Hopewell S, Altman DG, Emdin CA (2016) Atrial fibrillation and risks of cardiovascular disease, renal disease, and death: systematic review and metaanalysis. BMJ 354:i4482

3. Proietti M, Lip GYH (2016) Atrial fibrillation and stroke: making sense of recent observations on anticoagulation. Cardiol Clin 34:317-328

4. Freedman B, Potpara TS, Lip GYH (2016) Stroke prevention in atrial fibrillation. The Lancet 388:806-817

5. Huisman MV, Rothman KJ, Paquette M, Teutsch C, Diener HC, Dubner SJ et al (2015) Antithrombotic treatment patterns in patients with newly diagnosed nonvalvular atrial fibrillation: the gloria-af registry, phase II. Am J Med 128:1306-1313.e1

6. Camm AJ, Accetta G, Ambrosio G, Atar D, Bassand J-P, Berge E et al (2016) Evolving antithrombotic treatment patterns for patients with newly diagnosed atrial fibrillation. Heart. doi:10.1136/heartjnl-2016-309832

7. Wan Y, Heneghan C, Perera R, Roberts N, Hollowell J, Glasziou $P$ et al (2008) Anticoagulation control and prediction of adverse events in patients with atrial fibrillation: a systematic review. Circ Cardiovasc Qual Outcomes 1:84-91

8. Gallagher AM, Setakis E, Plumb JM, Clemens A, van Staa T-P (2011) Risks of stroke and mortality associated with suboptimal anticoagulation in atrial fibrillation patients. Thromb Haemost 106:968-977

9. Lau YC, Proietti M, Guiducci E, Blann AD, Lip GYH (2016) Atrial fibrillation and thromboembolism in patients with chronic kidney disease. J Am Coll Cardiol 68:1452-1464

10. Proietti M, Lane DA, Lip GYH (2016) Chronic kidney disease, time in therapeutic range and adverse clinical outcomes in anticoagulated patients with non-valvular atrial fibrillation: observations from the sportif trials. EBioMedicine. doi:10.1016/j. ebiom.2016.04.013

11. Lip GYH, Windecker S, Huber K, Kirchhof P, Marin F, Ten Berg JM et al (2014) Management of antithrombotic therapy in atrial fibrillation patients presenting with acute coronary syndrome and/or undergoing percutaneous coronary or valve interventions: a joint consensus document of the European Society of Cardiology Working Group on. Eur Heart J 35:3155-3179

12. Schlitt A, Rubboli A, Lip GYH, Lahtela H, Valencia J, Karjalainen PP et al (2013) The management of patients with atrial fibrillation undergoing percutaneous coronary intervention with stent implantation: in-hospital-data from the atrial fibrillation undergoing coronary artery stenting study. Catheter Cardiovasc Interv 82:E864-E870

13. Rubboli A, Schlitt A, Kiviniemi T, Biancari F, Karjalainen PP, Valencia $\mathbf{J}$ et al (2014) One-year outcome of patients with atrial fibrillation undergoing coronary artery stenting: an analysis of the AFCAS registry. Clin Cardiol 37:357-364

14. Lip GYH, Nieuwlaat R, Pisters R, Lane DA, Crijns HJGM (2010) Refining clinical risk stratification for predicting stroke and thromboembolism in atrial fibrillation using a novel risk factor-based approach: the euro heart survey on atrial fibrillation. Chest 137:263-272

15. Rosendaal FR, Cannegieter SC, van der Meer FJ, Briët E (1993) A method to determine the optimal intensity of oral anticoagulant therapy. Thromb Haemost 69:236-239

16. Connolly SJ, Pogue J, Eikelboom J, Flaker G, Commerford P, Franzosi MG et al (2008) Benefit of oral anticoagulant over antiplatelet therapy in atrial fibrillation depends on the quality of international normalized ratio control achieved by centers and countries as measured by time in therapeutic range. Circulation 118:2029-2037

17. Gallego P, Roldan V, Marín F, Romera M, Valdés M, Vicente $V$ et al (2013) Cessation of oral anticoagulation in relation to mortality and the risk of thrombotic events in patients with atrial fibrillation. Thromb Haemost 110:1189-1198

18. Bolton $\mathrm{K}$ et al (2002) K/DOQI clinical practice guidelines for chronic kidney disease: evaluation, classification, and stratification. Am J Kidney Dis 39:S1-S266

19. Thygesen K, Alpert JS, White HD, Jaffe AS, Apple FS, Galvani $M$ et al (2007) Universal definition of myocardial infarction. Circulation 116:2634-2653

20. Cutlip DE, Windecker S, Mehran R, Boam A, Cohen DJ, van Es G-A et al (2007) Clinical end points in coronary stent trials: a case for standardized definitions. Circulation 115:2344-2351

21. Lau YC, Hardy LJ, Philippou H, Blann AD, Lip GYH (2016) Altered fibrin clot structure in patients with atrial fibrillation and worsening renal function. Thromb Haemost 116:408-409

22. Go AS, Fang MC, Udaltsova N, Chang Y, Pomernacki NK, Borowsky L et al (2009) Impact of proteinuria and glomerular filtration rate on risk of thromboembolism in atrial fibrillation: the anticoagulation and risk factors in atrial fibrillation (ATRIA) study. Circulation 119:1363-1369

23. Friberg L, Rosenqvist M, Lip GYH (2012) Evaluation of risk stratification schemes for ischaemic stroke and bleeding in 182 678 patients with atrial fibrillation: the Swedish Atrial Fibrillation cohort study. Eur Heart J 33:1500-1510

24. Olesen JB, Lip GYH, Kamper A-L, Hommel K, Køber L, Lane DA et al (2012) Stroke and bleeding in atrial fibrillation with chronic kidney disease. N Engl J Med 367:625-635

25. Bonde AN, Lip GYHH, Kamper A-L, Hansen PR, Lamberts M, Hommel K et al (2014) Net clinical benefit of antithrombotic therapy in patients with atrial fibrillation and chronic kidney disease. J Am Coll Cardiol 64:2471-2482

26. Boriani G, Laroche C, Diemberger I, Popescu MI, Rasmussen LH, Petrescu L et al (2016) Glomerular filtration rate in patients with atrial fibrillation and 1-year outcomes. Sci Rep 6:30271

27. Piccini JP, Stevens SR, Chang Y, Singer DE, Lokhnygina Y, Go AS et al (2013) Renal dysfunction as a predictor of stroke and systemic embolism in patients with nonvalvular atrial fibrillation: validation of the R(2)CHADS(2) index in the ROCKET AF (Rivaroxaban Once-daily, oral, direct factor Xa inhibition 
Compared with vitamin $\mathrm{K}$ antagonism for prevention of stroke and Embolism Trial in Atrial Fibrillation) and ATRIA (AnTicoagulation and Risk factors In Atrial fibrillation) study cohorts. Circulation 127:224-232

28. Roldán V, Marín F, Manzano-Fernandez S, Fernández H, Gallego P, Valdés M et al (2013) Does chronic kidney disease improve the predictive value of the CHADS2 and CHA2DS2VASc stroke stratification risk scores for atrial fibrillation? Thromb Haemost 109:956-960

29. Banerjee A, Fauchier L, Vourc'h P, Andres CR, Taillandier S, Halimi JM et al (2013) Renal impairment and ischemic stroke risk assessment in patients with atrial fibrillation: the Loire Valley Atrial Fibrillation Project. J Am Coll Cardiol 61:2079-2087

30. Providência R, Marijon E, Boveda S, Barra S, Narayanan K, Le Heuzey J-Y et al (2014) Meta-analysis of the influence of chronic kidney disease on the risk of thromboembolism among patients with nonvalvular atrial fibrillation. Am J Cardiol 114:646-653

31. Apostolakis S, Guo Y, Lane DA, Buller H, Lip GYH (2013) Renal function and outcomes in anticoagulated patients with non-valvular atrial fibrillation: the AMADEUS trial. Eur Heart J 34:3572-3579

32. Banerjee A, Fauchier L, Vourc'h P, Andres CR, Taillandier S, Halimi JM et al (2014) A prospective study of estimated glomerular filtration rate and outcomes in patients with atrial fibrillation: the Loire Valley Atrial Fibrillation Project. Chest 145:1370-1382

33. De Caterina R, Husted S, Wallentin L, Andreotti F, Arnesen H, Bachmann F et al (2013) Vitamin K antagonists in heart disease: current status and perspectives (section III). Thromb Haemost 110:1087-1107

34. Chan EW, Lau WCY, Siu CW, Lip GYH, Leung WK, Anand S et al (2016) Effect of suboptimal anticoagulation treatment with antiplatelet therapy and warfarin on clinical outcomes in patients with nonvalvular atrial fibrillation: a population-wide cohort study. Hear Rhythm 13:1581-1588

35. Senoo K, Lip GYH (2016) Female sex, time in therapeutic range, and clinical outcomes in atrial fibrillation patients taking warfarin. Stroke 47:1665-1668

36. Pokorney SD, Simon DN, Thomas L, Fonarow GC, Kowey PR, Chang P et al (2015) Patients' time in therapeutic range on warfarin among US patients with atrial fibrillation: results from ORBIT-AF registry. Am Heart J 170:141-148.e1

37. Best PJM, Lennon R, Ting HH, Bell MR, Rihal CS, Holmes DR et al (2002) The impact of renal insufficiency on clinical outcomes in patients undergoing percutaneous coronary interventions. J Am Coll Cardiol 39:1113-1119

38. Maree AO, Margey RJ, Selzer F, Bajrangee A, Jneid H, Marroquin OC et al (2016) Renal insufficiency, bleeding and prescription of discharge medication in patients undergoing percutaneous coronary intervention in the national heart, lung, and blood institute (NHLBI) dynamic registry. Cardiovasc Revasc Med 17:302-327

39. Lahtela HM, Kiviniemi TO, Puurunen MK, Schlitt A, Rubboli A, Ylitalo A et al (2015) Renal impairment and prognosis of patients with atrial fibrillation undergoing coronary intervention-The AFCAS trial. PLoS One 10:e128492 